\title{
What are the Particularities of Gastric and Bariatric Surgery in the Cirrhotic Patient
}

\author{
Arnaud Pasquer ${ }^{1}$, Caroline Gronnier², Guillaume Piessen ${ }^{3}$ \\ 'Department of digestive and oncological surgery, Edouard herriot university hospital, 5 place d'arsonval 69003 Lyon, France \\ ${ }^{2}$ Esophageal and Endocrine Surgery Unit, Visceral Surgery Department, Magellan Center, Bordeaux University Hospital, Pessac, \\ France \\ ${ }^{3}$ Univ. Lille, Department of Digestive and Oncological Surgery, Claude Huriez University Hospital, F-59000 Lille, France
}

Corresponding author:

Professor Guillaume Piessen

Department of Digestive and oncological Surgery

Claude Huriez University Hospital

2 Avenue Oscar Lambret, 59000 Lille

France

E-mail: Guillaume.piessen@chru-lille.fr

\section{Rezumat}

Care sunt particularitățile chirurgiei gastrice și bariatrice la pacientul cirotic

Obiectivul acestei lucrări a fost de a trece în revistă întreaga literatură despre chirurgia gastrică şi bariatrică, pentru a defini în mod cât mai adecvat indicațiile chirurgicale şi specificul managementului lor terapeutic. Lucrarea se bazează pe publicațiile din PubMed şi Google Scholar din 1995 până în august 2015 folosind franceza şi engleza ca limbi de publicare. Au fost incluse 21 de studii (nivel 3 şi 4) din cele 128 identificate. În concluzie, dacă pacienții cirotici candidați la operație chirurgicală gastrică sunt selecționați în mod corespunzător, şansele de supraviețuire pe termen lung par relativ bune. $\mathrm{Nu}$ a fost raportat niciun risc de supraviețuire de lungă durată în aceste cazuri. Nu avem posibilitatea de a face recomandări chirurgicale bariatrice la pacientul cirotic din lipsă de date suficiente.

Cuvinte cheie: ciroza hepatică, chirurgia gastrică, chirurgia bariatrică
Received: 10.03 .2020

Accepted: 14.04 .2020

\section{Abstract}

The objective of this work was to review the entire literature on gastric and bariatric surgery in order to best define the surgical indications and the specifics of their management. A literature review from 1995 to August 2015 was conducted in Pubmed and 
Google Scholar, using French and English as publication languages. 21 studies were included (level 3 and 4) over 128 identified. In total, if the cirrhotic patients, candidates for gastric surgery, are appropriately selected, long-term survival seems relatively good. No risk factors for long-term survival have been reported. The literature data are insufficient to be able to make recommendations concerning bariatric surgery in the cirrhotic patient.

Key words: liver cirrhosis, gastric surgery, bariatric surgery

\section{Introduction}

This chapter reports the results of surgical studies conducted in gastric surgery-requiring cirrhotic patients. Most of the published articles have focused on surgical management-related immediate post-operative complications and/or mortality.

Cirrhosis severity scores have been studied as a risk factor for complications.

The main indications are primarily surgery for gastric cancer and secondarily bariatric surgery which constitute the two separate sub-chapters. The objective of this work was to review all of the literature on the subject in order to best define the surgical indications and the specifics of their management.

\section{Performed Research}

A literature review from 1995 to August
2015 was conducted in Pubmed and Google Scholar, using French and English as publication languages, with the following key words: "stomach" (mesh) and "liver cirrhosis" (mesh). 128 articles were identified among which 21 articles were selected after reading the summary and/or the article which dealt specifically with gastric surgery in the cirrhotic patient (Table 1).

\section{Surgical Indications}

Among the 21 studies selected, 17 dealt with surgery for gastric cancer and 4 for obesity.

The indication for gastric surgery was tumour in the majority of cases.

The main indication reported in the cirrhotic patients gastrectomy literature was tumour, and in particular stomach adenocarcinoma.

Table 1. Selected articles with level of evidence regarding gastric surgery in cirrhotic patients

\begin{tabular}{lc}
\hline Level of Scientific Evidence Provided by the Literature & Surgery ... \\
\hline Level 1 & 0 \\
High-power randomized controlled trials & \\
Meta-analysis of randomized controlled trials \\
Decision analysis based on well-conducted data & 0 \\
\hline Level 2 & \\
Low-power randomized controlled trials \\
$\quad$ Well-conducted non-randomized comparative studies \\
$\quad$ Cohort studies \\
\hline Level 3 \\
$\quad$ Case-control study & 2 \\
\hline Level 4 & 19 \\
$\quad$ Comparative studies with significant biases & \\
Retrospective studies & \\
$\quad$ Case series & 737 \\
\hline Number of Patients
\end{tabular}




\section{Gastric Cancer Surgery}

\section{Technical specificities}

There have been no reports in the literature assessing technical features such as haemostasis procedures in gastric canceroperated cirrhotic patients.

\section{Preoperator treatment}

In the Ikeda retrospective series, 3 out of 12 patients with preoperative esophageal varices had a portosystemic shunt with stability or postoperative remission (1).

Anecdotally, there is a case of liver transplantation in preparation for a gastrectomy for superficial cancer in a 64-year-old patient with decompensated cirrhosis (2). The lack of perspective on the recurrence risk under immunosuppressive therapy cannot recommend this attitude.

There are insufficient data in the literature to recommend preoperative treatment prior to gastric cancer surgery in cirrhotic patients.

\section{Approach way: laparoscopy or laparotomy}

Three retrospective cohort studies, two of which compared with laparotomy, looked at the potential benefits of laparoscopy on cancer post-gastrectomy postoperative follow-ups in the cirrhotic patient's subgroup.

Yoon et al. report a retrospective series comparing postoperative liver function in cirrhotic patients (Child A or B) with early gastric cancer in a group of 32 patients undergoing laparotomy distal gastrectomy versus 18 patients undergoing laparoscopic distal gastrectomy. Postoperative follow-ups were identical in terms of anastomotic fistula, sepsis and other severe morbidities. The serum albumin level at D7 was significantly higher in the laparoscopy group $(p=0.042)$ and the flow rate from the surgical drain at D2 was $25 \%$ lower $(p=0.013)$. Diuretic treatment was required postoperatively in $16.7 \%$ of patients operated by laparoscopy versus $18.7 \%$ of patients operated by laparotomy without significant difference $(p=0.587)(3)$.

Hwang et al. report a retrospective series of 632 patients undergoing laparoscopic gastrectomy between 2003 and 2007, the main objective of which was to study the morbidity risk factors in patients over the age of 70 by carrying out a study comparison between the group of patients under 70 versus over 70 years old. Multivariate analysis in the subgroup of 117 patients over the age of 70 identifies the existence of cirrhosis as an independent factor for postoperative complication (OR: 8.9, 95\% CI $=1.2-63.3, p=0.002$ ). The details of postoperative complications specifically linked to the existence of cirrhosis were not specified (4).

In a retrospective study, Kang et al retrospectively included 41 Child A cirrhotic patients with stage I $(n=28)$, stage II $(n=8)$, stage III $(n=4)$ and stage IV $(n=1) .13$ were operated on by laparoscopy and 28 by open route. There was no difference in terms of ascites, wall infection, deep abscess occurrence. The operating time was longer in the laparoscopy group, but it was not associated with an increase in complication rates $(p=0.969)(5)$

There is no data in the literature concerning total laparoscopic gastrectomy in the cirrhotic patient.

The laparoscopic approach is not inferior to the open route for distal gastrectomies for cancer in cirrhotic Child $A$ in terms of morbidity and reduces the refractory ascites risk (grade C). The laparoscopic approach is not recommended in cirrhotic patients over 70 years of age. Data are insufficient for Child $B$ and $C$ patients.

\section{Resection extension}

In the Ikeda series, the technical choice between a total or partial gastrectomy depended on gastric cancer location and type (1). When the tumor was localized in stomach's middle or distal third, a distal gastrectomy (48\%) was carried out. In the event of an invasive tumor, a total gastrectomy was performed (40\%). A wedge resection ( $12 \%$ ) was 
proposed in patients suffering from superficial lesion caused by impaired hepatic function or when it was necessary to perform a portosystemic shunt, simultaneously. Resection extent-depending postoperative follow-up is not detailed in this series.

The gastrectomy extension does not seem to influence postoperative treatment (6).

The proposed gastrectomy extension is established according to the tumour location: distal gastrectomy in case of antral cancer (Grade A).

\section{Extension of lymph node ablation}

In the Ikeda series, D1 lymph nodes ablation $(58.8 \%)$ was most often used and no difference was found between D1, D2 and D3 ablations in terms of postoperative complications $(p=0.411)$ or incurable ascites $(p>0.999)(1)$. Just as in the study by Jang et al., where there was no evidence of an increase in ascites in the case of cure D2 (7).

However, in the series by Guo et al., a significant increase in refractory ascites was demonstrated in the case of D2 ablation (71.9\%) compared to D1 ablation $(29.2 \%)$ in Child A and B ( $p=0.003)$. In addition, there was a $50 \%$ mortality in Child B patients who had a D2 ablation linked to the hepatoduodenal ligament ablation, which constitutes the source of postoperative refractory ascites (8).

$D 1$ cleaning in Child $B$ cirrhosis is recommended to minimize the risk of refractory ascites and postoperative mortality. D2 cleaning in Child A cirrhosis is feasible.

\section{Abdominal drain}

Four studies report abdominal drainage $(3,6$, $9,10)$. The type of drainage is not specified except that it is a closed drainage (9) in one study and it is a suction drainage in the other 3 studies. Drainage was removed after refeeding and if the daily flow rate was less than $150-200 \mathrm{~mL}(3,9)$. The drainage influence on postoperative complications is not reported. In Child A and B patients, a drainage volume peak was observed on the $5^{\text {th }}$ postoperative day in the absence of haemorrhage, fistula or liver failure, whereas in the presence of one of these complications, the drain flow did not decrease during the second postoperative week. A nonsignificant increase in morbidity $(p=0.055)$ was demonstrated in the Ho Lee series in the abdominal drainage group 47.4 to $27 \%$ in the drain-free group (6).

The course of action relating to abdominal drainage in the particular context of gastric surgery in the cirrhotic patient cannot be discussed. No recommendations can be made on issues of short-term drainage or lack of drainage. The ascites fluid infection can be detected by a count of the ascites fluid, as in the other surgical indications for the cirrhotic patients.

\section{Short-term Results}

\section{Operational data}

Surgery duration

Only one study mentions operating times (3). There is no evidence of difference between the laparoscopic route and the laparotomy for distal gastrectomy in the cirrhotic patient $(223.4 \mathrm{~min} \pm 54.4$ vs $192.5 \mathrm{~min} \pm 63.2$ respectively, $\mathrm{p}=0.336$ ).

\section{Blood loss}

Only one study mentions blood loss in gastric surgery in cirrhotic patients. There was no significant difference between the patients Child A $(759 \mathrm{~mL}$ [79-2705]) and B (1103 mL [182-3073], $p=0.336)$ (1).

\section{Post-surgery period}

\section{Complications}

Cirrhosis was identified as an independent predictor of postoperative complications subsequent to gastric cancer surgery, in a retrospective series of 759 patients (OR $=2.4$ [0.9-6.5], all the more so in the case of cirrhosis Child B $\left(\mathrm{OR}=9.8[0.7-115.5]^{\circ}\right.$ than Child A (OR = 8.4 [2.8-25.3]) (10). In this study, the existence of a major comorbidity including a disease heart and/or cirrhosis was linked to 
an increase in the rate of anastomotic fistulas, intraabdominal collection, postoperative bleeding, pulmonary complication, arrhythmia and renal failure compared to the group without comorbidities. However, the postoperative complications directly attributable to the presence of cirrhosis were not detailed.

The results of a prospective study including 2,107 patients operated on for gastric cancer confirm that cirrhosis is an independent risk factor for postoperative morbidity at 30 days $(\mathrm{OR}=3.13,95 \% \mathrm{CI}: 1.15-8.48)(10)$. Again, the specific complications of cirrhosis were not detailed.

In addition, cirrhosis was also identified as an independent risk factor for duodenal stump fistula subsequent to gastric surgery for cancer in a large retrospective study of 1,287 gastrectomies, including 51 performed in cirrhotic patients (OR: 13.3, $\mathrm{p}<0.001)$ (8). The cirrhosis stage was not detailed.

In these three studies, the morbidity rate was not detailed by grades of cirrhosis severity.

The most frequently reported postoperative complications in gastric cancer surgery cirrhotic patients are:

- postoperative ascites (6.7 to $40 \%$ );

- wall infections (8.7 to $18.2 \%$ );

- hepatic encephalopathy (4.3 to $36.3 \%$ );

- anastomotic fistula (2\%).

Postoperative ascites is more common in Child B patients (40-67.7\%) than Child A $(6.7-36 \%)(1,9)$. In most cases, ascites was treated conservatively with diuretics, and possible paracentesis realization. The transfusion notion and the ASAT rate were morbidity independent predictors in the series by Ho Lee et al. The anastomotic fistula rate did not appear to be increased compared to non-cirrhotic patients.

The pre-existence of cirrhosis increases the risk of post-operative morbidity, in particular duodenal stump fistula. Special care is recommended in the treatment of the duodenal stump with stapling and overlocking (expert opinion).

\section{Hospital Stay}

Only one study reported length of stay. In the Ikeda series, the length of hospital stay did not differ between Child A and B for a median length of stay of 13.5 days [7-90].

\section{Post-surgery mortality}

The data concerning post-operative mortality are quite heterogeneous (2.1-19\%). Nevertheless, the trend towards an exponential increase with the increase in Child's score emerges. In the Fengua series, the mortality was $4 \%$ for the Child A group, $25.8 \%$ in the Child B group and $100 \%$ in the Child C group.

Only the Japanese study (1) did not find any significant difference in terms of postoperative mortality which may be linked to a lack of potency.

The primary cause of postoperative death was liver failure.

The preoperative predictors of mortality in cirrhotic patients undergoing gastrectomy are:

- the degree of liver failure reflected in the Child score;

- an ASAT rate higher than 40;

- extensive ablation of the hepatoduodenal ligament responsible for massive postoperative ascites.

The cirrhotic patient treated for gastric carcinological surgery is at risk of severe complications and significantly higher mortality even if not all the studies document it precisely. Data from the literature suggest that cirrhosis is a risk factor for morbidity and duodenal stump fistula.

\section{Risk factors for morbidity and mortality}

\section{Child-Pugh score}

Whilst in the Ikeda series there was no evidence of overall excess morbidity in Child B patients, this is not confirmed in 2 studies $(7,9)$ where there is a significant increase in severe postoperative complications in Child B patients, and $\mathrm{C}$ versus Child A patients.

Thus, in the study by Joo Jang et al. (7), postoperative mortality was significantly 
higher in Child B / C cirrhotic patients than A: $27.2 \%$ versus $4.3 \%(p=0.045)$, as well as in the Guo study (Child B 25.8\% versus Child A $4 \%$, $\mathrm{p}=0.033)$.

It is not recommended to perform a gastrectomy in a Child $C$ (Grade $C$ ) patient.

\section{MELD Score}

The MELD score was not specified in the series studied.

\section{Portal hypertension}

The portal hypertension assessment was not detailed in the studies.

The place of TIPS called preventive or "neoadjuvant" has not been evaluated in these studies.

The scores evaluating the underlying liver disease are correlated with post-operative complications. Child-Pugh scores should be used to assess risk and to guide operative decision. Classes $B$ and Cde Child-Pugh are associated with higher morbidity and mortality. No recommendation can be made on the TIPS site, but it must be discussed on a case-by-case basis.

Long-term results: survival, adjuvant therapy, quality of life

\section{Quality of life}

There is no data in the literature to assess the quality of life after gastric surgery in the event of cirrhosis.

\section{Long-term survival}

Regarding survival, the prognosis of cirrhotic patients seems to be worse than that of non-cirrhotic patients at comparable stage. After excluding postoperative mortality, the main cause of death is related to cirrhosis complications, such as hepatocellular insufficiency, bleeding complications and liver cancer $(11,12)$

Overall, a 5-year survival rate varies between $41.1 \%-65.9 \%(1,9,11): 59.9 \%-69.7 \%$ for early cancers and $13.9 \%-33.3 \%$ for advanced cancers. Child A patients have a better 5-year survival than Child B (60 vs $30.5 \%, p=0.089)$. The causes of death were mainly recurrent cancer for advanced lesions and HCC for patients with early cancer.

In the case of suitable selection of gastric surgery cirrhotic patients candidates, longterm survival seems relatively good. No risk factors for long-term survival have been reported.

\section{Optimization before surgery of the cirrhotic patient}

There are no studies focusing, in the context of gastric surgery, on preoperative optimization and rehabilitation (nutritional status, exercise rehabilitation, physiotherapy, anti-thrombotic prophylaxis, antibiotic prophylaxis, prevention hepatorenal syndrome).

No specific recommendation can be made on the preparation of the cirrhotic patient for pancreatic surgery. In the case of portal hypertension, the establishment of a TIPS can be discussed, although its benefit has not been demonstrated.

\section{Place of non-surgical alternatives}

Alternatives to surgery (RCT or RT, local treatments, endoscopic Ttt).

\section{Endoscopic treatment}

In a series of 18 cirrhotic patients, Ogura et al showed the feasibility of endoscopic resection of superficial block gastric neoplastic lesions in $88.9 \%$ of cases, at the cost of an increase in late bleeding in $3 / 18$ patients including one required endoscopic haemostasis (13).

In a prospective study including 928 patients and 1,016 superficial gastric neoplastic lesions resections (14), the presence of cirrhosis $(n=18)$ did not lead to an increase in operating time, nor in the rate of incomplete or "peace" resection meal ", intraoperative bleeding, perforation, or increase in hospital stay compared to the control group. In this series, $72 \%$ of Child A was cirrhosis. 
In a propensity score adjustment retrospective study, including 69 cirrhotic patients ( $77 \%$ Child A), the endoscopic submucosal ablation postoperative consequences in superficial gastric neoplasia did not differ compared to the control group, between the Child A group and $\mathrm{B} / \mathrm{C}$ group. The 5-year survival rate was, however, lower in the cirrhosis group than in the control group (60 vs 91\%) linked to hepatocellular carcinoma. Cirrhotic patients without a history of hepatocellular carcinoma had a 5-year survival almost equivalent to the control group (15).

An oesophageal varices adjacent superficial cancer endoscopic resection is reported with varices simultaneous treatment with cyanoacrylate in a cirrhotic Child A patient, with a satisfactory result (16).

These studies possible criticism is a selection bias, since most of them have almost exclusively Child A patients, making a rigorous and reliable comparison difficult to obtain.

Endoscopic resection for superficial cancers can be proposed as an alternative in cirrhotic patients (grade $C$ ).

\section{Radiotherapy - chemotherapy:}

There are no literature reports of specific studies on radiotherapy or chemotherapy as an alternative to surgery in a cirrhotic patient with gastric cancer.

\section{Bariatric Surgery and Cirrhosis}

The bariatric surgery benefits for certain obesity-related conditions such as diabetes have been clearly demonstrated (17). Recent data suggest that bariatric surgery in patients with fatty liver disease reduces its degree. Keshishian et al. reported a 60\% reduction in fatty liver at 3 years after a duodenal switch.

However, in patients with proven cirrhosis the problem of postoperative morbidity persists. Few articles have specifically studied bariatric surgery in the cirrhotic patient. Shimizu et al. reported a series of 23 cirrhotic patients undergoing bariatric surgery (14 gastric bypass, 8 sleeve gastrectomy and a gastric band) of which 21 were Child A (18). The overall complication rate reported was $34 \%$ or 8 patients (an anastomotic fistula, 2 anastomotic strictures, a hematoma superinfected after gastric bypass, a fistula on sleeve gastrectomy, bleeding on line of staples). After 12 months of follow-up for 18 patients, the excess weight loss reached $67.4 \%$ $\pm 30.9 \%$.

Rebibo et al. studied, in a case-control study, the sleeve gastrectomy results in 13 cirrhotic patients compared to 26 non-cirrhotic patients. The cirrhosis aetiology was NASH and the patients were Child A in all cases. There was no evidence of difference in terms of overall complications $(7.7 \%$ versus $7.7 \%, p=1)$, or of serious complications ( 0 versus $7.7 \%, p=0.22$ ). In this series, cirrhosis was diagnosed intraoperatively in all cases and confirmed by biopsy (19).

Heimbach et al. report a series of 7 patients who underwent a sleeve gastrectomy in preparation for a liver transplant compared to a group of 37 patients following a medical program to lose weight before liver transplantation. In the sleeve + transplant group, there was no postoperative mortality, versus 3 years the control group. A sleeve gastrectomy was complicated by a fistula with multiple reoperations but ultimately a good function of the graft (20).

The literature data are insufficient to be able to make recommendations concerning bariatric surgery in the cirrhotic patient.

\section{Conflict of Interest}

The authors declare no conflicts of interests.

\section{Acknowledgements}

We thank the Société Francaise de Chirurgie Digestive (SFCD) and the Association de Chirurgie Bilio-Pancreatique (ACHBT) for their support.

\section{References}

1. Ikeda Y, Kanda T, Kosugi S, Yajima K, Matsuki A, Suzuki T, et al. Gastric cancer surgery for patients with liver cirrhosis. World $J$ Gastrointest Surg. 2009;1(1):49-55. 
2. Nishimura S, Saeki H, Ikegami T, Ando K, Yamashita Y, Oki E, et al. Living donor liver transplantation followed by total gastrectomy--a two-stage planed operative strategy for early gastric cancer concomitant with decompensated liver cirrhosis. Anticancer research. 2014;34(8):4307-10.

3. Yoon HM, Yang HK, Lee HJ, Park DJ, Kim HH, Lee KU, et al. Comparison of liver function after laparoscopically assisted and open distal gastrectomies for patients with liver disease. Surgical endoscopy. 2011;25(6):1761-5.

4. Hwang SH, Park DJ, Jee YS, Kim HH, Lee HJ, Yang HK, et al. Risk factors for operative complications in elderly patients during laparoscopy-assisted gastrectomy. J Am Coll Surg. 2009; 208(2) 186-92.

5. Kang SJ, Jung MR, Cheong O, Park YK, Kim HG, Kim DY, et al. Is Laparoscopy-assisted Radical Gastrectomy Safe in Patients with Child-Pugh Class A Cirrhosis? J Gastric Cancer. 2013;13(4):207-13.

6. Lee JH, Kim J, Cheong JH, Hyung WJ, Choi SH, Noh SH. Gastric cancer surgery in cirrhotic patients: result of gastrectomy with D2 lymph node dissection. World J Gastroenterol. 2005 11(30):4623-7.

7. Jang HJ, Kim JH, Song HH, Woo KH, Kim M, Kae SH, et al. Clinical outcomes of patients with liver cirrhosis who underwent curative surgery for gastric cancer: a retrospective multi-center study. Dig Dis Sci. 2008;53(2):399-404.

8. Orsenigo E, Bissolati M, Socci C, Chiari D, Muffatti F, Nifosi J, et al. Duodenal stump fistula after gastric surgery for malignancies: a retrospective analysis of risk factors in a single centre experience. Gastric Cancer. 2014;17(4):733-44.

9. Guo F, Ma S, Yang S, Dong Y, Luo F, Wang Z. Surgical strategy for gastric cancer patients with liver cirrhosis: a retrospective cohort study. Int J Surg. 2014;12(8):810-4.

10. Jeong O, Kyu Park Y, Ran Jung M, Yeop Ryu S. Analysis of 30-day postdischarge morbidity and readmission after radical gastrectomy for gastric carcinoma: a single-center study of 2107 patients with prospective data. Medicine (Baltimore). 2015;94(11):e259.

11. Isozaki $H$, Okajima K, Ichinona T, Fujii K, Nomura E, Izumi N.
Surgery for gastric cancer in patients with cirrhosis. Surg Today. 1997;27(1):17-21.

12. Takeda J, Hashimoto K, Tanaka T, Koufuji K, Kakegawa T. Review of operative indication and prognosis in gastric cancer with hepatic cirrhosis. Hepatogastroenterology. 1992;39(5):433-6

13. Ogura K, Okamoto $M$, Sugimoto $T$, Yahagi N, Fujishiro $M$, Kakushima N, et al. Efficacy and safety of endoscopic submucosal dissection for gastric cancer in patients with liver cirrhosis. Endoscopy. 2008;40(5):443-5

14. Kwon YL, Kim ES, Lee KI, Kim YJ, Park CW, Kim YJ, et al. Endoscopic treatments of gastric mucosal lesions are not riskier in patients with chronic renal failure or liver cirrhosis. Surgical endoscopy. 2011;25(6):1994-9.

15. Kato M, Nishida T, Hamasaki T, Kawai N, Yoshio T, Egawa S, et al. Outcomes of ESD for patients with early gastric cancer and comorbid liver cirrhosis: a propensity score analysis. Surgical endoscopy. 2015;29(6):1560-6.

16. Kim YS, Cho WY, Cho JY, Jin SY. Successful treatment of early gastric cancer adjacent to a fundal varix by endoscopic submucosal dissection and endoscopic cyanoacrylate therapy. Clin Endosc. 2012;45(2):169-73

17. Pequignot A, Dhahri A, Verhaeghe P, Desailloud R, Lalau JD, Regimbeau JM. Efficiency of laparoscopic sleeve gastrectomy on metabolic syndrome disorders: two years results. J Visc Surg. 2012;149(5):e350-5.

18. Shimizu H, Phuong V, Maia M, Kroh M, Chand B, Schauer PR, et al. Bariatric surgery in patients with liver cirrhosis. Surg Obes Relat Dis. 2013;9(1):1-6.

19. Rebibo L, Gerin O, Verhaeghe P, Dhahri A, Cosse C, Regimbeau JM. Laparoscopic sleeve gastrectomy in patients with NASH-related cirrhosis: a case-matched study. Surg Obes Relat Dis. 2014;10(3): 405-10; quiz 565

20. Heimbach JK, Watt KD, Poterucha JJ, Ziller NF, Cecco SD, Charlton $\mathrm{MR}$, et al. Combined liver transplantation and gastric sleeve resection for patients with medically complicated obesity and endstage liver disease. Am J Transplant. 2013;13(2):363-8. 